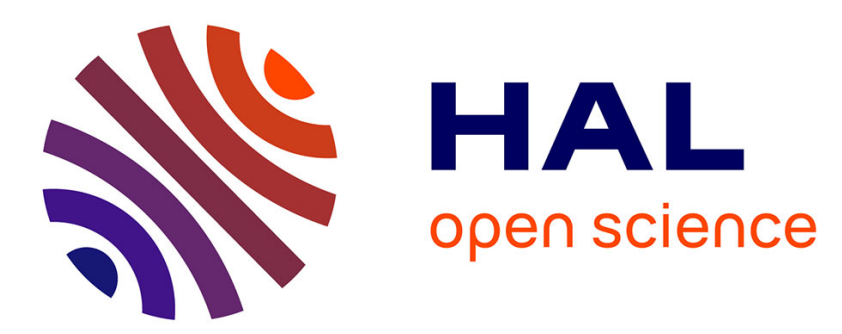

\title{
Extreme Sea Conditions in Shallow Water: Estimations Based on In-Situ Measurements
}

Izan Le Crom, Yves Perignon, Jean-Baptiste Saulnier, Christian Berhault

\section{To cite this version:}

Izan Le Crom, Yves Perignon, Jean-Baptiste Saulnier, Christian Berhault. Extreme Sea Conditions in Shallow Water: Estimations Based on In-Situ Measurements. ASME 2013 32nd International Conference on Ocean, Offshore and Arctic Engineering, Jun 2013, Nantes, France. 10.1115/OMAE201310752 . hal-01157616

\author{
HAL Id: hal-01157616 \\ https://hal.science/hal-01157616
}

Submitted on 14 Sep 2020

HAL is a multi-disciplinary open access archive for the deposit and dissemination of scientific research documents, whether they are published or not. The documents may come from teaching and research institutions in France or abroad, or from public or private research centers.
L'archive ouverte pluridisciplinaire HAL, est destinée au dépôt et à la diffusion de documents scientifiques de niveau recherche, publiés ou non, émanant des établissements d'enseignement et de recherche français ou étrangers, des laboratoires publics ou privés.

\section{(c)(1)}

Distributed under a Creative Commons Attribution| 4.0 International License 


\section{EXTREME SEA CONDITIONS IN SHALLOW WATER: ESTIMATIONS BASED ON IN-SITU MEASUREMENTS}

\author{
Izan Le Crom \\ LHEEA, Ecole Centrale de Nantes \\ Nantes, France \\ Jean-Baptiste Saulnier \\ LHEEA, Ecole Centrale de Nantes \\ Nantes, France
}

\author{
Yves Perignon \\ LHEEA, Ecole Centrale de Nantes \\ Nantes, France \\ Christian Berhault \\ LHEEA, Ecole Centrale de Nantes \\ Nantes, France
}

\begin{abstract}
This paper focuses on the assessment of the environmental extreme conditions in term of wind and waves at the SEMREV wave energy test site for application in the design of Marine Renewable Energy (MRE) devices and components. The paper will first present the existing in situ wind and wave measurements. A prediction chain from global to regional scales, and based on a regional wave model calibrated at the SEMREV location, is then described. It enables to build a specific 22 year hindcast dataset for the test site. Long term extrapolation is finally achieved at the SEMREV location using existing methodologies for deep water conditions. Long term extrapolations methods are usually very sensitive to the parameterization and configuration of the prediction chain and we demonstrate in this study that the best overall performances are reached by a POT method at this stage of development in the prediction chain.
\end{abstract}

\section{INTRODUCTION}

The wave energy test site SEM-REV is running through a development schedule since October 2007. Consents have been granted in 2010/2011 and installation works finished in October 2012. The test facility will be fully operational by mid-2013.

Operations on site are supervised from the ECN land station of Pen Avel in Le Croisic - west coast of France - by a dedicated team with all the required equipment to ensure operability, security and safety of data acquisition, energy converter, control and survey. The SEMREV restricted area $\left(1 \mathrm{~km}^{2}\right.$, Figure 1) is located 12 nautical miles offshore in about 35 meters L.A.T of water depth and opened to Atlantic Ocean's conditions. The SEMREV test site is bordered on his east side

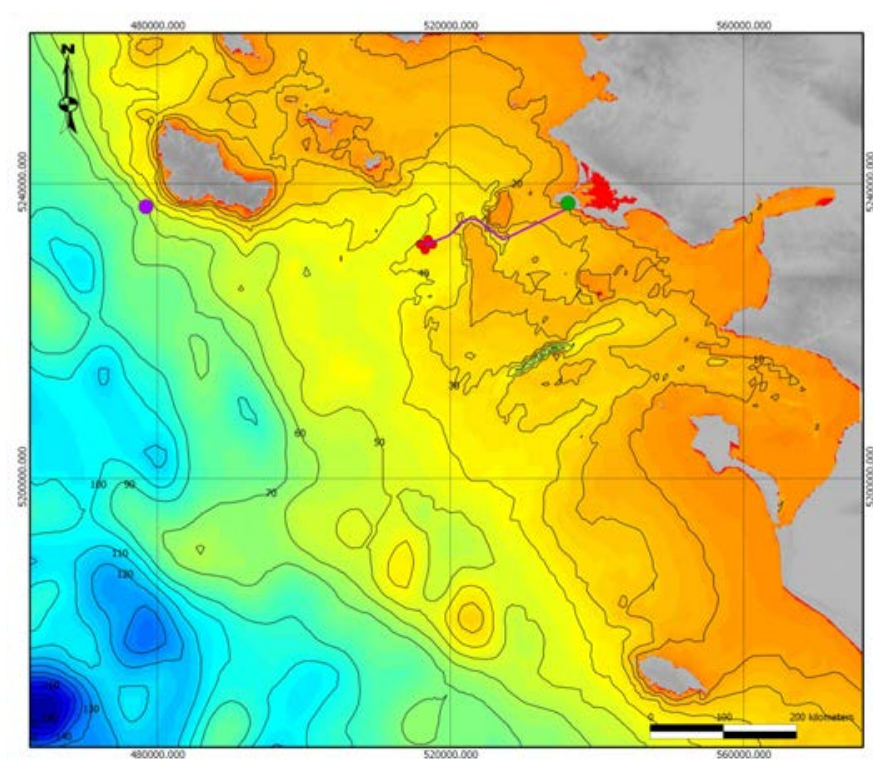

Figure 1 Onshore base and station (green dot), electrical cable (purple line), offshore test zone location (4 red dots for the special marks), and DWR Belle-île (purple dot).

by two shoals (Figure 2, "Banc de Guérande" and "Plateau du Four"). A 8MVA cable connects the test site to an electrical substation nearby the onshore base, which grants access to the local grid. Environmental and system operation control data are transmitted in real time from the offshore test site to the land base through optical fibers. The cable will be associated to a subsea connector by mid-2013 for a first phase of exploitation, and a central subsea hub is planned to enable the connection of several independent test slots by mid-2014. 


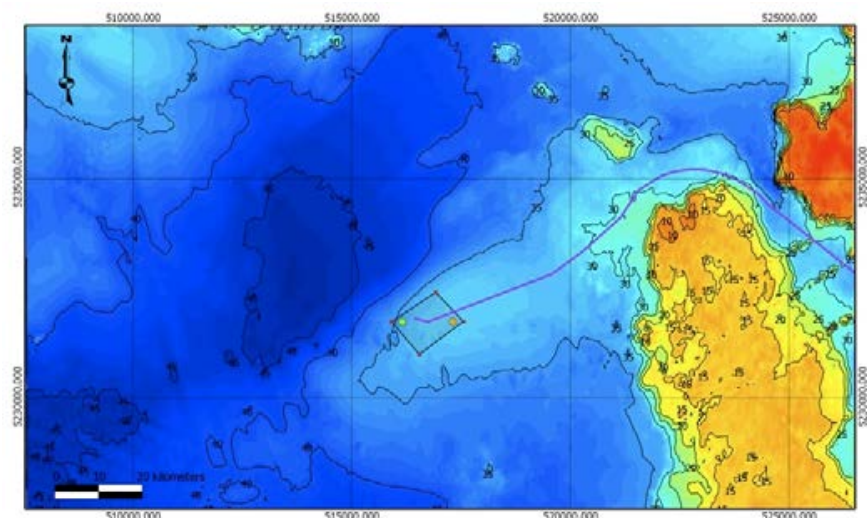

Figure 2 Chart based on the interpolation of the bathymetric data collected by the SHOM close to the SEMREV. Cable (purple line), site perimeter (black), east and west DWR (color dots). WGS 84 coordinates.

The SEM-REV test site has been equipped with a set of sensors monitoring the environmental conditions since 2009. The instrumentation comprises an array of directional Waverider buoys (DWR). East and West buoys are located inside SEMREV and DWR Belle-île is located some $40 \mathrm{~km}$ westward from the site, offshore of the south coast of "Belle-Ile-en-Mer". An acoustic Doppler current profilers (ADCP) has been used to assess the currents and water levels on site. Measurements of wind and atmospheric parameters are performed by a meteorological buoy (BMTO) moored on the test zone. The deployment timeline of the met-ocean sensors is summarized in the Figure 3.

The design of Marine Renewable Energy (MRE) devices and components is based, among others, on the assessment of the environmental extreme conditions (winds, currents, waves, and water level) that must be combined together in order to evaluate the maximal loads on a floating/fixed structure, and on its anchoring system. Dimensioning a wave energy converter (WEC) for shallow water conditions remains a not fully solved task and the matter of combining different loads will not be addressed in this paper. We will rather focus here on the evaluation of wind and waves extreme conditions.

The assessment of those extreme conditions at sea for a given return period (typical order of tenth of years for dimensioning purposes) generally results from the use of extrapolation methods. However, because of a too high uncertainty level when applied to short duration in-situ reference data, an extrapolation method cannot be directly applied to the 3 years SEMREV measurements. It is however commonly admitted to apply an extrapolation method to hindcast data from a wave model calibrated with real measurements [1]. This indirect use of in-situ data is crucial for the extrapolation as it enables a qualification of the overall accuracy of a wave model. As a case study, existing methodologies for the assessment of environmental condition in deep water have been applied to the SEMREV test site. The modeling chain used for the generation of the wave hindcast data set over 22 years (hereinafter

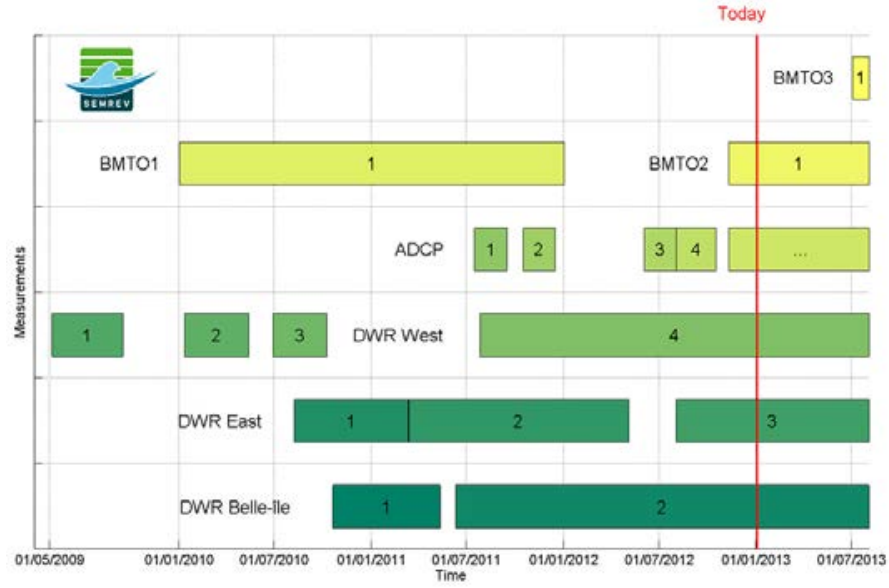

Figure 3 Gantt diagram for the deployment of met-ocean instrumentation on SEMREV.

empirical data) is first described here. The hindcast data set is qualified in a second part through a comparison to in situ measurements. Extrapolation methods based on statistical distributions are then applied to fit wind and wave data and to provide larger return periods. Their results are discussed and some recommendations to improve the simulation of wave conditions are finally reviewed.

\section{WAVE MODEL}

A 22-year hindcast simulation (from 01/01/1989 to 28/02/2011) was performed with a combination of the spectral wave models WAVEWATCH III ${ }^{\mathrm{TM}}$ [2] (hereafter WWATCH) for the global grid and SWAN [3] for the regional grid (Simulating Wave Near Shore version 40.85). WWATCH is parameterized by Dodet et al. (2010), [4], following recommendations from Ardhuin et al. (2009) [5]. ERA-Interim data are used as wind input instead of the original NCEP/NCAR data due to their better performances in this configuration [6]. The ERA-Interim data set provided by the European Centre for Medium-Range Weather Forecasting (ECMWF) enables to force the model with 6-h wind fields.

The global WWATCH wave hindcast data set provides 6-h input 2D spectra over 32 frequency and 24 directions to the regional grid at its west and south borders (west border following the longitude $3.5^{\circ} \mathrm{W}$ from $46.5^{\circ} \mathrm{N}$ to $47.5^{\circ} \mathrm{N}$, and south border following the latitude $46.5^{\circ} \mathrm{N}$ from $3.5^{\circ} \mathrm{W}$ to $2.0^{\circ} \mathrm{W}$ ). From then, the SWAN model was used to compute the wave evolution in the coastal region and complete the prediction chain up to the SEM-REV test site. Once again the ERA-Interim 6-h wind fields force the model with a spatial resolution of $0.75^{\circ}$. A coarse computation grid $(2 \mathrm{~km}$ resolution over a $115 \times 112 \mathrm{~km}$ area) provides boundary conditions to a refined nested grid $(500 \mathrm{~m}$ resolution over a $60 \times 44 \mathrm{~km}$ area, including SEMREV and "Belle-Ile-en-Mer" island) (Figure 4). The bathymetric grids for both domains are based on raw high resolution data issued by SHOM (Service Hydrographique et Océanographique de la Marine). The SWAN model is run in a $3^{\text {rd }}$ generation mode, taking into account a linear wind growth, 
the exponential wind growth and with-capping term by Janssen (1991), a the bottom friction related to Madsen (1988)'s [3] formulation, as well as depth induced breaking and quadruplet and triad non-linear source terms. The model is set to run in quasi-stationary mode and to output two sets of results, as plotted on Figure 4:

- the 2D energy spectrum at 2 different locations (center of the zone and DWR Belle-île).

- the main spectral parameters across the whole domains (coarse and fine grids).

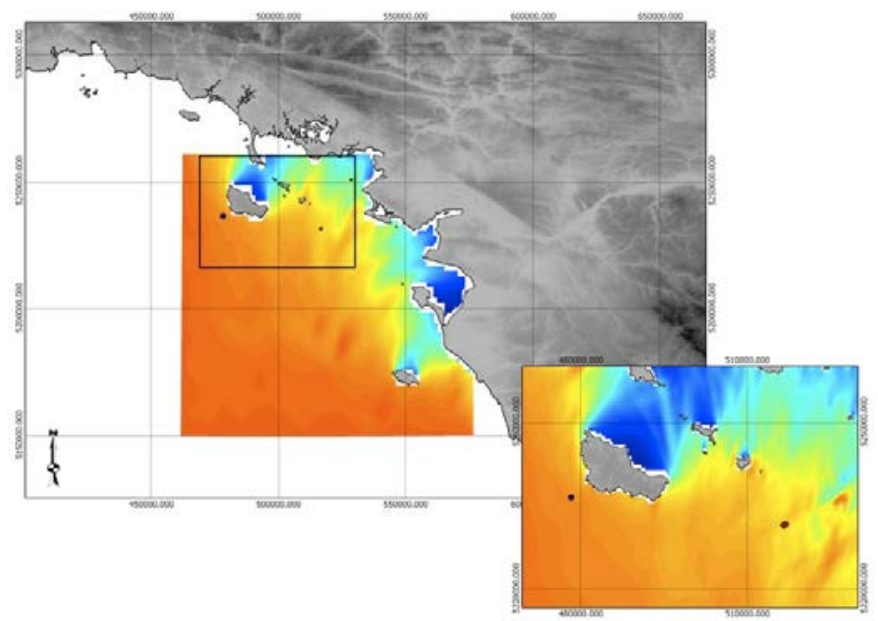

Figure 4: Illustration of the Hs repartition on the coarse and fine (nested) grids. Model outputs locations (center of the zone and DWR Belle-île).

\section{CALIBRATION AND QUALIFICATION}

The overall quality of the model chain is assessed using the following definition of the normalized root mean square error (NRMSE) for the comparison to reference data:

$$
\text { NRMSE }=\sqrt{\frac{\sum(\text { Xobs }- \text { Xnum })^{2}}{\sum \text { Xobs }^{2}}}
$$

Hindcast data stemming from the global model have been previously validated by in-situ measurements (6 DWR buoys). In the study using NCEP/NCAR wind input [4], comparisons between measured and modeled data lead for instance to NMRSE of approximately $26 \%$ for 6-h average Hs in Sines (depth $97 \mathrm{~m}$ ), or $20 \%$ in Leixões (depth $83 \mathrm{~m}$ ), over a 3 years period (1993-1995). The overall performances of the global grid will directly impact those of the regional one, and the former studies provide some reference values in term of typical accuracy at the regional scale.

The 2D output spectrum from the SWAN model (at the center of the zone) and the ones stemming from the 2 DWR Buoys located on site allow to perform a comparison between three selected spectral parameters $\mathrm{Hs}, \mathrm{T}_{\mathrm{p}, \mathrm{R} 5}, \theta \mathrm{m}$, respectively the significant wave height, the wave peak period computed by the Read method of order 5, and, the mean wave direction. An interpolation of the $6 \mathrm{~h}$ parameters (outputs from the SWAN wave model) is performed to fit the hourly synthetic parameters computed from buoy measurements.

As described in [7], the parameterizations of the wave models, such as the ones at use here, are generally unable to reproduce the conditions during extreme storms (even if improvements have been achieved ever since). In those extreme conditions, the description and parameterization of the physics reaches some limits of validity. We can list among them issues related to the ability of atmospheric model to provide accurate high speed winds, to the ability of wind-wave forcing term to account for the proper momentum transfers, or to the adequacy of whitecapping terms. This generally results in an underestimation of the largest wave heights. In order not to "miss the peaks" a qualification of the regional model accuracy is performed on 6 identified extreme events that is over 6 measurement periods with the highest Hs values (Table 1). Note that the event number 2, characterized by the maximum $\mathrm{Hs}$ (i.e., 6.1m), in February 2010, is known as the Xynthia storm.

Table 1: Extreme events measured by the in situ DWR buoys.

\begin{tabular}{|c|c|c|c|}
\hline Date & Hs max (m) & Om ( $\left.{ }^{\circ}\right)$ & $\operatorname{Tp}(\mathbf{s})$ \\
\hline $03 / 02 / 201018: 00-10 / 02 / 201018: 00$ & 4.4 & 247 & 13.8 \\
\hline $21 / 02 / 201018: 00-28 / 02 / 201018: 00$ & 6.1 & 240 & 11.4 \\
\hline $25 / 03 / 201006: 00-05 / 04 / 201006: 00$ & 4.4 & 243 & 11.4 \\
\hline $07 / 11 / 201012: 00-16 / 11 / 201000: 00$ & 4.5 & 247 & 10.3 \\
\hline $06 / 01 / 201100: 00-19 / 01 / 201100: 00$ & 5.1 & 244 & 12.5 \\
\hline $09 / 02 / 201118: 00-18 / 02 / 201106: 00$ & 3.4 & 230 & 13.8 \\
\hline
\end{tabular}

The method employed here for a regional calibration consists in minimizing the relative error (NRMSE) between the measured and modeled spectral parameters. To do so, the tuning coefficients in the parameterization of bottom friction, whitecapping, and wind growth were varied independently in their respective admissible physical ranges. With an additional optimization criterion based on a slight overestimation of the maximum $\mathrm{Hs}$ for each extreme event, it was found that the standard values for the Jansen's formulation (wave growth and dissipation) and for the Madsen's friction source term were providing the overall best performances for events number 2 to 5 (Table 2). For event number 1 and 6, the default parameters are not optimal but the NRMSE does not vary much from its optimal value (not shown here). Moreover, this specific calibration process on the most extreme events directly results in an overestimation of the sea state parameters during lower energetic sea states. In that sense, the relative error resulting from this calibration is not generally optimal, except for the specific energetic events for which it was calibrated. 


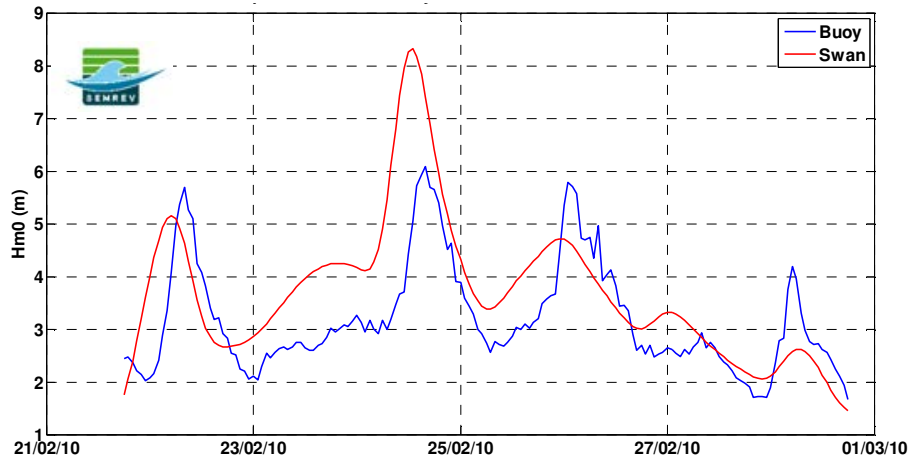

Figure 5: Comparison between buoy measurements and Swan model estimates (Hs) during the event Xynthia.

During the Xynthia event, the comparison between measured and modeled Hs does not show a particularly good agreement (Figure 5 \& Table 2). If the main peak of the storm is term of $\mathrm{Hs}$ is overestimated, three modeled secondary peaks show lower Hs than the measured ones. However, the WWATCH global model already presents offshore the same tendency, and the regional SWAN model simply propagates the misfit to shore. The parameterization at use here in the global model is responsible for a strong overestimation of young and steep waves as shown in [5]. We can note that a more recent parameterization (Ardhuin et al., 2010 [8]) used in Bertin et al. (2012) [9] is now able to reproduce quite satisfactory the temporal evolution of mean wave parameters during Xynthia.

Table 2: Comparison of model outputs to measurements (NRMSE as defined earlier).

\begin{tabular}{|c|c|c|c|c|}
\hline Event & Hs max (m) & Hs (\%) & Om (\%) & Tp (\%) \\
\hline 1 & 4.4 & 59 & 8 & 36 \\
\hline 2 (Xynthia) & 6.1 & 34 & 5 & 22 \\
\hline 3 & 4.4 & 22 & 3 & 19 \\
\hline 4 & 4.5 & 30 & 3 & 33 \\
\hline 5 & 5.1 & 37 & 3 & 28 \\
\hline 6 & 3.4 & 42 & 3 & 31 \\
\hline
\end{tabular}

The general agreement of model output to measurement seems acceptable for the other events. High values of $\mathrm{Hs}$ are reasonably overestimated, as shown for instance, in the QQ plot of Hs during the event number 5 (Figure 6). All incident mean directions are properly taken into account by the prediction chain (as presented by the low NRMSE values in Table 2).

The modeled peak periods are generally overestimated compared to measurements, but the general tendency seems to be captured by the model as presented here for the most accurately resolved event (Event number 3, Figure 7).

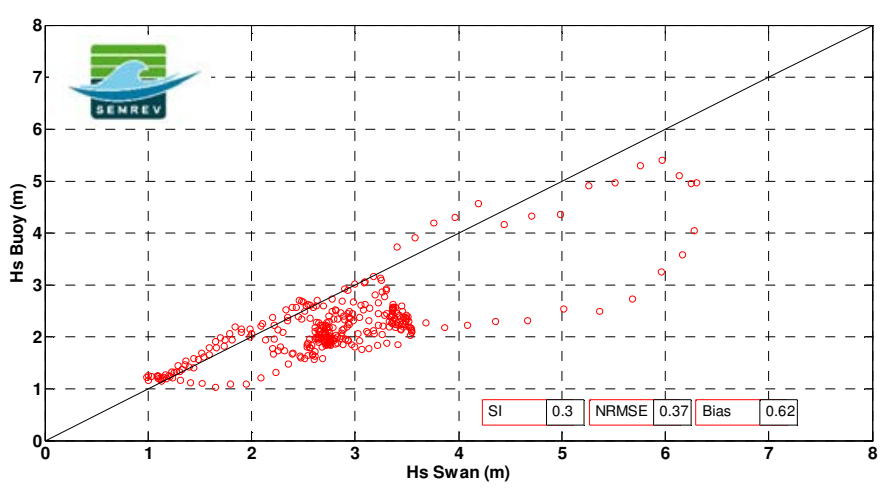

Figure 6: Comparison between buoy measurements and Swan model estimates (Hs) during the event number 5.

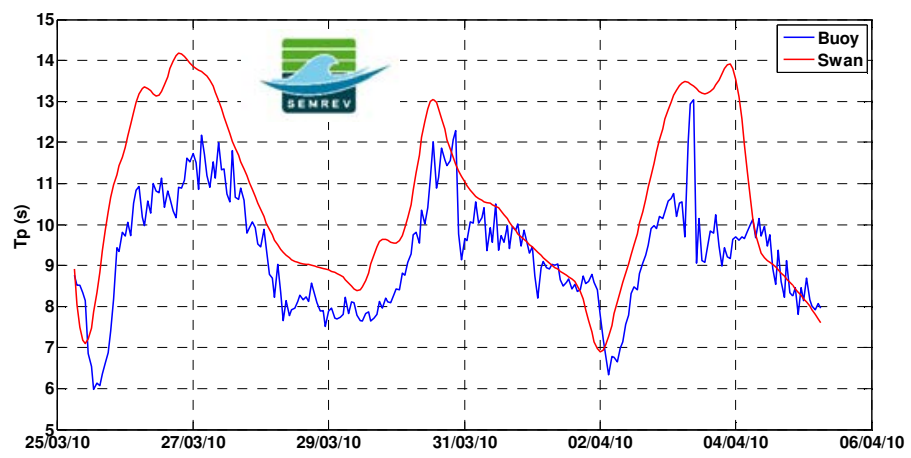

Figure 7: Comparison between buoy measurements and Swan model estimates $\left(\mathrm{T}_{\mathrm{p}, \mathrm{R} 5}\right)$ during the event number 3 .

\section{LONG TERM EXTRAPOLATION METHODS}

Several long term extrapolation methods are applied to the ERA Interim wind hindcast data set and to the wave hindcast data previously described.

As a first step, the Initial Distribution Approach (IDA) [10], combined with a 'censoring' process enabling all values above a given threshold to be used for the extrapolation, is applied to the 33 years wind data set. Figure 8 presents the results of this method in the case of a threshold set to $15 \mathrm{~m} / \mathrm{s}$. The probability function of occurrence, ordinate of the graph, is expressed by

$$
\mathrm{F}=1-\frac{1}{\mathrm{X} * \lambda}
$$

where $\mathrm{X}$ corresponds to the return period in years and $\lambda$ to a correction factor for the time scales and related to the censoring and data resolutions by

$$
\lambda=1-\frac{\mathrm{N}}{\left(\mathrm{t}_{\text {end }}-\mathrm{t}_{\text {start }}\right)} \times \frac{1}{\mathrm{f}},
$$

with $\mathrm{N}$ the total number of elements, $\mathrm{t}_{\text {start }}$ and $\mathrm{t}_{\mathrm{end}}$ the initial and final date in years, and $f$ the yearly number of data. Lastly, fitting a Weibull statistical distribution to the measured data leads to a satisfactory agreement (Figure 8). If the statistical solution slightly overestimates the extreme values for short 
return periods $(20.5 \mathrm{~m} / \mathrm{s}$ for a return period of about 3 years $)$, the modeled 33-years maximum wind speed $23.7 \mathrm{~m} / \mathrm{s}$ lies conservatively within the confidence interval of the statistical law.

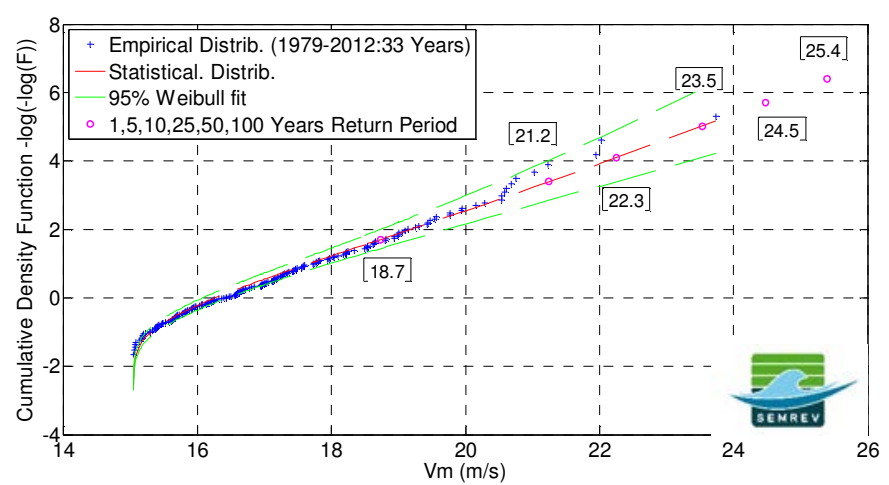

Figure 8: IDA applied to Vm values (from ERA) for a $15 \mathrm{~m} / \mathrm{s}$ threshold. Statistical distribution, Weibull fitting, 95\% confidence interval and representative return values.

The IDA method is then applied to the 22-year wave hindcast data set computed with the SWAN regional model. For a too low threshold, the Weibull distribution does not fit properly to the modeled data and the statistical solution systematically overestimates the highest empirical values (not shown here). After some trial and error, the best fit of the statistical distribution seems to be provided by a threshold set to $5.5 \mathrm{~m}$ (Figure 9). Still, the Weibull fitting is not able to provide an appropriate extrapolation method as some of the long term return values remain underestimated (e.g. second highest value has a higher return period than statistical estimation).

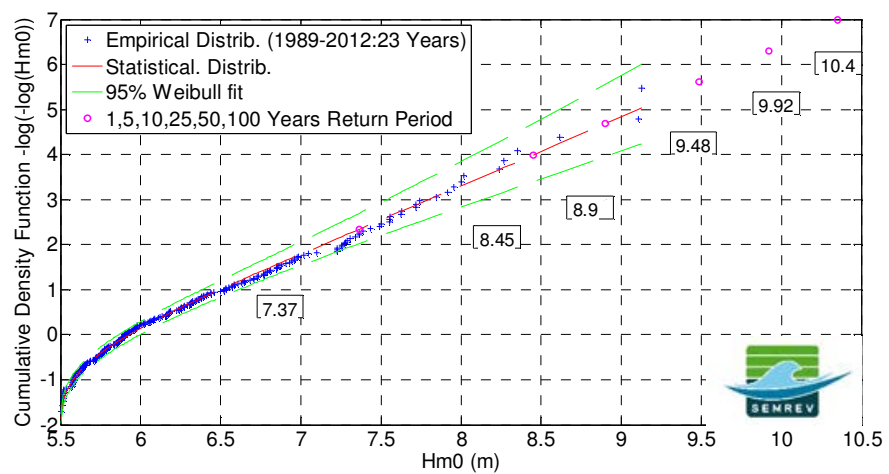

Figure 9: IDA applied to Hs values (from SWAN) for a $5.5 \mathrm{~m}$ threshold. Statistical distribution, Weibull fitting, 95\% confidence interval and representative return values.

Moreover, if the IDA leads to a relatively good correlation with the modeled data and is a commonly used approach, it remains an empirical method that does not respect the extreme values theory. The dataset selected for the extrapolation needs to be independent and identically distributed [10], which isn't the case for the 6-hourly Hs output from the wave model data set.
In that sense, the wave conditions might be more persistent than the wind conditions for the same sampling frequency. The Annual Block Maxima (ABM) method cannot either be applied in this case as it sets the extrapolation fit on a really small sample of points. This results in an overall underestimation of the extreme values (not pictured). The Peak Over Threshold (POT) provides a third approach which remains consistent with the extreme values theory. This method is based on the selection of samples whose reference value (Hs here) lies above a given threshold and for which a minimal time interval has to be verified. This ensures that several extreme values related to the same extreme event cannot contribute altogether to the statistical law.

The estimation of the threshold remains a crucial question to address. It is determined here thanks to two methods, both implemented in the WAFO toolbox [11]:

- mean residual life plot, mean excess relatively to the threshold - dispersion index plot, normalized dispersion ratio.

Both methods are based on the adjustment of a standard statistical distribution (respectively, Pareto and Poisson) over the extreme part of the empirical distribution. The lowest threshold estimated from both methods shall provide a value high enough to keep accuracy and low enough to provide a proper sampling size.

The selected data for a POT extrapolation with threshold set to $4.3 \mathrm{~m}$ are presented Figure 10. The correlation of the Pareto distribution to the wave modeled data is pictured Figure 11. The statistical fitted distribution presents a proper overall tendency compared to the empirical model data. It predicts for instance a significant height of $9.17 \mathrm{~m}$ for a 25 years return period, when the empirical maximum wave height reached $9.13 \mathrm{~m}$ in December 1989 for this 22-year dataset. Moreover, the latest measurements from the end date of the dataset to December 2012 remain in agreement with this fit. During the Joachim storm, occurring mid December 2011, the maximum Hs reached $8.2 \mathrm{~m}$. According to the POT statistical fit, such an extreme sea state can be seen as a 5-year return period event.

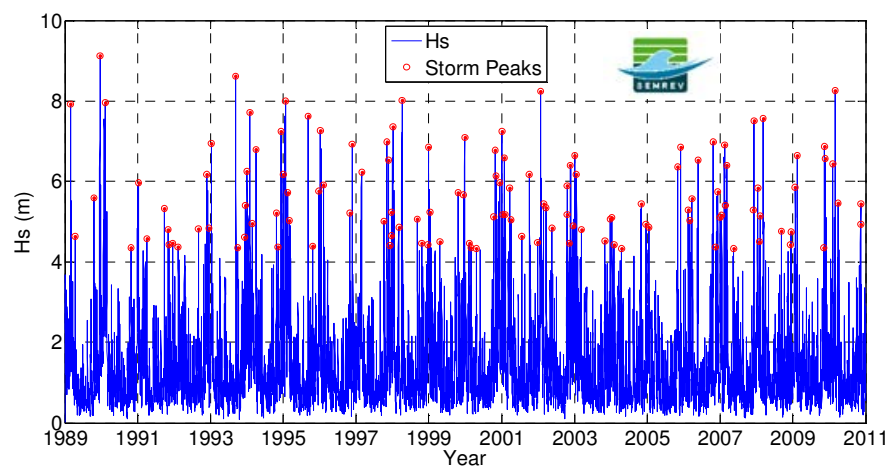

Figure 10: Identification of the extreme events process for an illustrative threshold of $4.3 \mathrm{~m}$ and storms separation set to 1 week. 


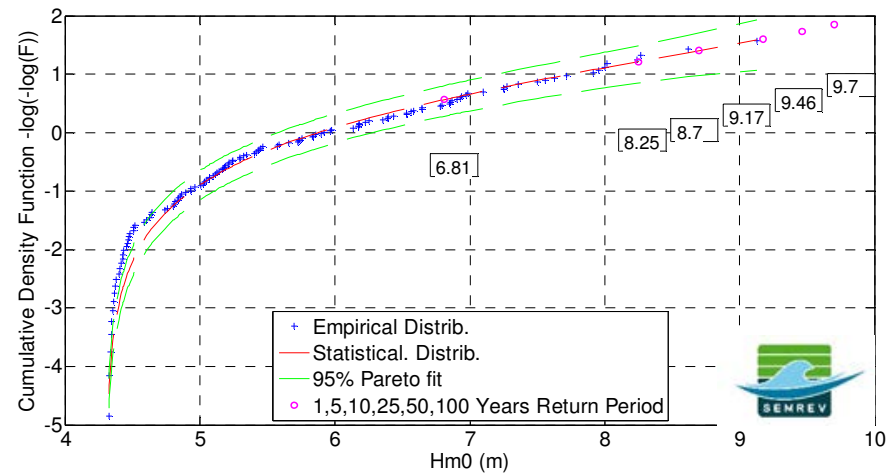

Figure 11: POT applied to Hs values (from SWAN) for a $4.3 \mathrm{~m}$ threshold. Statistical distribution, Pareto fitting, 95\% confidence interval and representative return values.

For longer return periods, results have to be considered cautiously as the uncertainty tied up to these values will increase significantly. In order to verify the choice of this threshold a sensitivity study based on the evolution of the 25years return period is carried out. Figure 12 shows that for a threshold high enough, a certain convergence in term of return value seem to occur. The choice of the $4.3 \mathrm{~m}$ threshold is consistent as it compares well with the results observed for higher thresholds. At this stage, such a combination of a Pareto distribution with a POT method provides the best fit to our hindcast dataset.

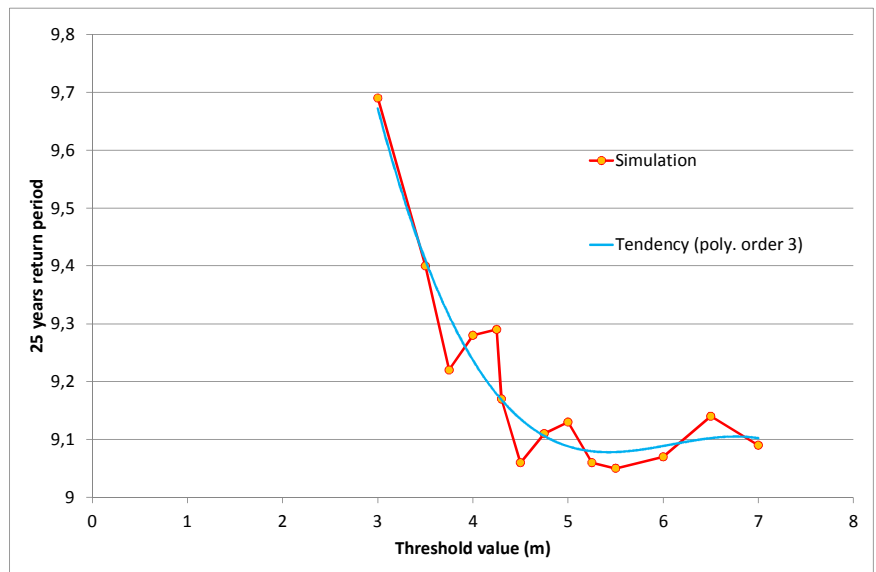

Figure 12: 25-years return period evolution in function of the threshold value for the POT extrapolation method.

Once the extrapolation properly fits the modeled data of the significant wave height, the necessity for assessing the other characteristic spectral parameters arises. If a relation between the most energetic sea states and parameters such as $\mathrm{T}_{\mathrm{p}, \mathrm{R} 5}, \mathrm{H}_{\max }$ or $\gamma$ (JONSWAP spectral peak enhancement parameter) remain complex to establish, some directional properties are more straightforward to assess for the SEMREV test site. When studying the properties of main directions for the wave fields, the POT method previously described can easily be applied to some specific angular sectors. When defining angular bins of $22.5^{\circ}$, the interval $\left[236.25^{\circ}-258.75^{\circ}\right]$ (south-west direction) accounts for the highest probability of occurrence with about $50 \%$ of the sea states originated from this set of directions. Moreover, the largest significant wave heights are included in this bin. It is therefore consistent to associate the integrated multi-directional results presented in Figure 11 with a mean direction of $247.5^{\circ}+/-11.25^{\circ}$. The extrapolation applied in this sector gives very similar results to the multi-directional case.

\section{CONCLUSIONS}

The specific application of long-term extrapolation methods has been presented here for wind and wave extreme values on the SEMREV coastal test site.

Wind data have been studied in term of intensity through the ERA-Interim data set, and a censored-IDA extrapolation method combined to a Weibull fit employed here. This method has been demonstrated to provide a satisfactory conservative estimation of the extreme wind return values.

A different methodology has been applied to the long-term extrapolation of extreme sea states. A wave model chain has been built from a global WWATCH domain to a regional SWAN set up, so as to account for the proper physical evolution of wave in the SEMREV coastal region. The model results have then been qualified and calibrated at the regional scale to specifically provide the best conservative estimations for extreme wave conditions. The calibration has been achieved on several parameters related to usual source term in the SWAN wave model. The standard tuning coefficient have finally provided the best overall results in term of relative error between the significant height from the model chain compared to in situ measurements for several extreme events. A 22-year wave hindcast data set has been built accordingly, and various extrapolation methods have been tested. An IDA method combined with a proper threshold and Weibull distribution has provided a first fit which, despite its apparent accuracy, does not grant a conservative estimation. It emphasizes the need for a proper independent and identically distributed dataset for the good performances of this method. Due to the small size of the data sample, an ABM method is not suitable either here. A POT method combined with an appropriately estimated threshold, a Pareto distribution and a given time interval finally provides the best overall conservative fit to the hindcast wave dataset. An analysis of mean direction of origin for the most extreme events finally emphasizes the predominant southwest influence.

Atmospheric models are not always properly calibrated for extreme conditions. ERA-Interim data were selected due to their 33-year duration, reducing therefore the uncertainty of a long term extrapolation. However the use of the 1-h wind fields from NCEP/CFSR [12] could provide a refinement of the representation of the storm peaks.

Despite its higher time consumption, the direct simulation approach (DSA) used for the creation of the wave hindcast data set seems physically more coherent and, is preferred to the propagation of an already extrapolated synthetic extreme event. 
Several improvements able to provide a better accuracy to the simulation of wave conditions can already be listed as:

- the account for a more recent parameterization (latest physics refinement from [8]) in the global domain. A run of the year 2011 with this formulation and a 1-hour forcing time step for the unmodified SWAN nesting provides an overall better accuracy compared to measurements on site. The Joachim event (December 2011) pictured on figure 13 and Table 3 provides some insight of the performances of this formulation. - the refinement of the space resolution in the regional domain, through an unstructured grid would provide for instance a better estimation of the shadowing due to Belle-île

- the integration of tidal currents and water level variations all over the regional grid. The macro-tidal environment in this area has already been proved to be able to influence significantly the propagation of sea states through the refraction by currents [13], and in specific configurations through the varying shadow with tide created by a chaotic bathymetry up-wave.

- the refinement of the time resolution for the wind forcing fields. The current 6-hourly ERA-Interim dataset is inherently interpolated in time in the WWATCH global domain simulation. An hourly data set would enable a better description of the wind forcing conditions.

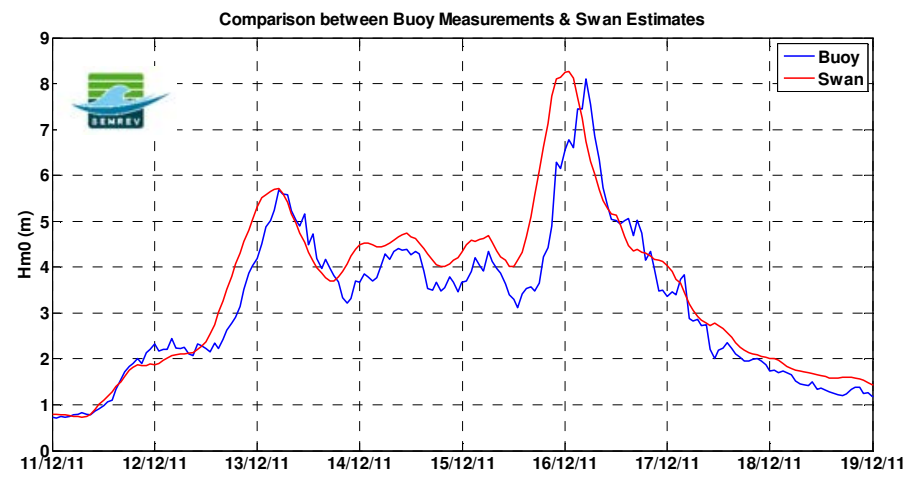

Figure 13: Comparison between buoy measurements and SWAN model estimates (Hs) during the event Joachim. New parameterization of the WWATCH global model.

Table 3: Comparison of model outputs to measurements (NRMSE).

\begin{tabular}{|c|c|c|c|c|}
\hline Event & Hs max (m) & Hs (\%) & Om (\%) & Tp (\%) \\
\hline 7(Joachim) & 8.2 & 18 & 4 & 22 \\
\hline
\end{tabular}

\section{ACKNOWLEDGMENTS}

The authors are grateful to X. Bertin for 'forcing' this study, kindly providing WWATCH input data for the regional model, and to the company Actimar for their valuable comments. Many thanks go to G. Le Bihan, P. Rousselot and H. Lugez, responsible for getting high quality measurements from the harsh field.

\section{REFERENCES}

[1] Prevosto, M., 2011. Extremes and Long Term Extrapolation. Deliverable D2.6. www.equimar.org

[2] NOAA WAVEWATCH III, http://polar.ncep.noaa.gov/waves/index2.shtml

[3] Simulating WAves Nearshore, version 40.85, http://swanmodel.sourceforge.net/

[4] Dodet, G.,et al. 2010. Wave climate variability in the North-East Atlantic Ocean over the last six decades. Ocean Modelling 31 (3-4), 120-131.

[5] Ardhuin, F.,et al. 2009. Observations of swell dissipation across oceans. Geophysical Research Letter 36, L06607. doi:10.1029/2008GL037030.

[6] ECMWF Interim Reanalysis Data Archive, http://www.ecmwf.int/products/data/archive/descriptions/ei/ind ex.html

[7] Cavaleri, L., 2009. Wave Modelling - Missing the Peaks. American Meteorological Society 39, 2757-2778.

[8] Ardhuin, F., et al. 2010. Semiempirical dissipation source functions for ocean waves. Part I: definition, calibration, and validation. Journal of Physical Oceanography 40, 19171941.

[9] Bertin, X., et al.2012. Importance of wave age and resonance in storm surges: The case Xynthia, Bay of Biscay Ocean Modelling 42, 16-30.

[10] Holthuijsen, L.H., 2007. Waves in Oceanic and Coastal Waters, Cambridge University Press.

[11] WAFO Toolbox http://www.maths.lth.se/matstat/wafo/ [12] NCEP/CFSR http://rda.ucar.edu/pub/cfsr.html

[13] Ardhuin, F. et al. 2012: Numerical Wave Modeling in Conditions with Strong Currents: Dissipation, Refraction, and Relative Wind. J. Phys. Oceanogr., 42, 2101-2120. 